\title{
$\left.\mathbf{C}^{-}\right\rceil$CONGRESO
INTERNACIONAL \\ SOBRE \\ LF_O FOTOGRAFÍA
}

Congreso Internacional sobre Fotografía

UPV, 5 y 6 octubre 2017

Doi: http://dx.doi.org/10.4995/CIFo17.2017.6883

ISBN: 978-84-9048-604-7

\section{Imág nes post-matern en instagram: el selfie como narrativa personal}

\section{Gemma San Cornelio ${ }^{a}$}

a Estudis de Ciències de la Informació i la Comunicació, grup de recerca Mediaccions, Universitat Oberta de Catalunya

\begin{abstract}
In the present paper I present a case study developed within the framework of the Selfiestories and personal data research project (financed by the BBVA Foundation, 2014-2017). Using a hybrid methodology that combines a quantitative and a qualitative approach, some Instagram profiles belonging to women who had published selfies shortly after giving birth are analyzed, in order to understand the different narratives about motherhood that emerge from these profiles.
\end{abstract}

Keywords: personal narrative, selfie, maternity, identity

\begin{abstract}
Resumen
En la presente comunicación se presenta un estudio de caso desarrollado en el marco del proyecto de investigación Selfiestories y personal data (financiado por la fundación BBVA, $2014-$ 2017). Utilizando una metodología híbrida que combina una aproximación cuantitativa y una cualitativa se analizan algunos perfiles de Instagram pertenecientes a mujeres que habian publicado selfies poco después de haber dado a luz, con el fin de comprender las distintas narrativas sobre la maternidad que se desprenden de estos perfiles .
\end{abstract}

Palabras clave: narrativa persnal, selfie, maternidad, identidad. 
Imág nes post-matern en instagram: el selfie como narrativa personal

\section{Introducción}

Las redes sociales constituyen hoy en dia el escenario de grandes desencuentros, discusiones y conversaciones agitadas que revelan posicionamientos radicales en relación a prácticamente cualquier tema: desde la política al nuevo peinado de una celebrity. Por otra parte, estamos asistiendo en los últimos años a la proliferación de discursos relacionados con el parto, el cuidado de los hijos, su alimentación, vacunas, etc. que Internet y las redes sociales amplifican de un modo considerable. En otras palabras, la elección de una opción entre las distintas formas de afrontar la maternidad obliga, en cierta manera, a tener siempre a mano un posicionamiento concreto en relación con cada una de las decisiones tomadas. Esta situación es relativamente nueva y es un reflejo más de la sociedad de la información en la que nos hemos adentrado, asi como también refleja un cambio en las percepciones y el modo en que la información sobre como criar a los hijos se ha producido de forma tradicional. En la actualidad, la necesidad de informarse desde el mismo momento del embarazo, pasando por el parto y las distintas fases de la crianza de los hijos nos convierte en expertas (o aspirantes a expertas) en todas y cada una de estas facetas a la vez que provoca en determinadas personas la urgencia de comunicar todo este proceso en Internet (Barassi, 2017; Leaver, 2015).

Los blogs y redes sociales constituyen espacios de discusión que ponen de manifiesto diferentes formas de afrontar la maternidad que, aunque múltiples, se podrían simplificar en las denominadas 'guerras de madres' que se dividen entre aquellas que trabajan en casa y las que trabajan fuera (Green, 2012; Lopez, 2009; Peskowitz, 2005). Ambas posiciones entran en conflicto con la cultura occidental del trabajo, lo cual produce a una situación de inevitable pérdida para las mujeres: tanto para las que eligen una opción como la otra. Esta dualidad es un punto de discusión inicial que a lo largo de esta comunicación permitirá adentrarnos en las diferentes sensibilidades y tensiones producidas entre las mujeres que publican contenido relacionado con su maternidad y, aquellas que comentan sobre este mismo tema en las redes sociales.

\section{Objetivos}

El objetivo principal de esta comunicación es analizar el tipo de narrativas personales y discursos que emergen a través de la publicación y discusión de imágenes relacionadas con la maternidad en Instagram. Perteneciente al proyecto de investigación Selfiestories y personal data (financiado por la fundación BBVA, 2014-2017), se presenta un estudio de caso centrado en el seguimiento a lo largo de dos años a varias usuarias de la red social Instagram, aplicando etnografía digital -principalmente observación participante- y acompañado de un análisis cuantitativo. Más concretamente, los perfiles seleccionados corresponden a mujeres que publicaron un selfie -un autorretrato con la cámara del móvil, generalmente compartido en redes sociales- poco después de haber dado a luz, acompañados de un pie de foto donde se reivindicaba el cuerpo natural, en oposición a las imágenes de cuerpos perfectamente modelados que a menudo muestran determinadas celebrities, incluso después del parto. A partir de aquí se analizará si existe un tipo de narrativa personal focalizada en temas relacionados con este momento vital y por extensión con la maternidad en general.

\section{Marco conceptual: el selfie como narrativa personal}

Considerar el selfie como narrativa personal implica superar su condición intrínseca de imagen, y entenderlo como un artefacto comunicativo que circula por las redes sociales. Los selfies, por tanto, constituyen algo más que una representación (Gómez y Thornham, 2015), incorporando elementos sociales y conversacionales, que en un momento dado pueden devenir en controversia. En este contexto, Fallon se ha acercado al fenómeno 
dentro del espectro más amplio de la relación entre las imágenes y los hilos narrativos de los 'feeds' (Fallon, 2014). También merece la pena mencionar la visión de Georgakopolou de los selfies como 'pequeñas historias', incluyendo en su análisis, las voces de personajes y narradores. Según esta autora, "el selfie se comparte como una representación y/o se responde como una historia" (Georgakopolou, 2016, p.315), de manera que los comentarios e interacciones que desencadenan son una parte intrínseca de la misma, que se puede extender potencialmente hasta que se agota la conversación. En esta misma línea, también resulta muy interesante la aproximación de Gunthert (2014) a la fotografía digital como 'imagen conversacional'.

A principios del año 2016 aparecieron en algunos medios digitales referencias a dos selfies que habían sido publicados por mujeres poco después del parto. Ambas publicaciones venían a mostrar en su perfil de instagram como queda el cuerpo de la mujer poco después del parto. De entrada, el mensaje que comparten estas dos imágenes, buscando representar a la mujer 'real', es muy pocas veces asociado al selfie, quedando éste generalmente relegado a una lectura negativa vinculada al narcisismo e individualismo (San Cornelio, Roig, Ardèvol, 2017). Por tanto, este tipo de selfie intenta trasladar una un mensaje de normalización del cuerpo de la mujer después del parto, una imagen generalmente idealizada y distorsionada por algunas celebrities que muestran cuerpos perfectos poco después de dar a luz.

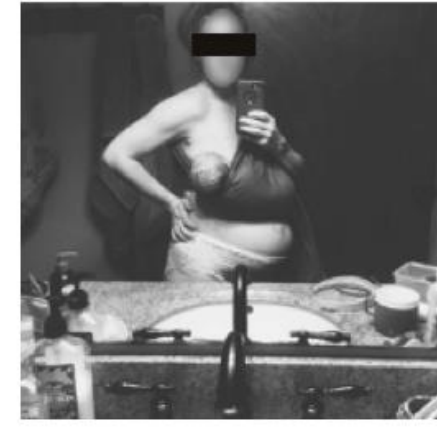

This is what 24 hours postpartum looks like. Baby in sling. Skin to skin. Adult diapers. And a rosy glow. My body feels like it ran a marathon and my heart is wide open from yesterday's travels

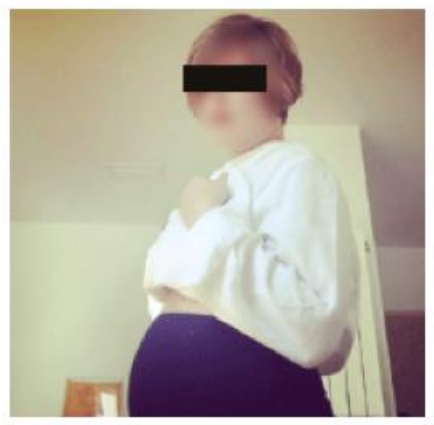

Hoy hace 7 semanas que después de 28 horas de parto provocado me hicieron una cesárea y sacaron a lo más bonito del mundo para mi y os seré honesta así está mi cuerpo hoy parece que sigo embarazada

Fig. 1 y 2, imágenes y pies de foto que tomamos como punto de partida en la investigación

Esta narrativa generada por oposición a un canon tiene resonancias a algunos arquetipos sociales vinculados con la maternidad que vendrían a representar, de un lado, a la mujer sexualmente atractiva y bien arreglada, que mezcla la maternidad con el glamour. Esta idea se contrapone con la de la mujer 'que se ha dejado', perezosa y poco femenina (Goodwin \& Huppatz, 2010, p. 85). De este modo, a partir de esta oposición podemos entender que las mujeres elegidas para este estudio de caso se sitúan en el lado de las mujeres 'normales', o 'reales' renegando de los atributos construidos socialmente (el cuerpo perfecto). Sin embargo, como se irá desarrollando en la comunicación, irán apareciendo otras dualidades y contradicciones. 


\section{Desarrollo de la investigación}

\subsection{Metodología}

A diferencia de otros proyectos sobre selfies con un enfoque únicamente cuantitativo (Manovich, 2013, Bruno et al, 2014) u otras investigaciones cualitativas (Senft y Baym, 2015), en el proyecto selfiestories hemos optado por desarrollar un "método mixto" (Markham, 2013). Esta perspectiva está justificada por la necesidad de enriquecer los datos cuantitativos con los datos cualitativos llevando a cabo trabajo de campo etnográfico para comprender mejor las diferentes formas de narrativas personales y, por otro lado, adoptar un enfoque Big Data orientado al análisis de enormes conjuntos de datos. Para dar cuenta de ello, hemos desarrollado nuestro propio extractor de datos basado en la API de Instagram que se ha utilizado para diferentes estudios de caso. En este caso concreto se extrajeron datos de la aplicación instagram relativas estas dos usuarias, que cuentan con perfiles públicos y abiertos. El extractor devolvió información relacionada con la imagen y los siguientes metadatos: hashtag, subtítulos y comentarios, fecha y hora de subida, usuarios y contabilización de 'likes', entre otros. Además, ambas usuarias fueron contactadas personalmente, aunque sólo una de ellas entabló conversación, así que por motivos éticos y de confidencialidad, omitiremos los detalles personales y las denominaremos Sylvia (figura 1) y Marina (figura 2). Para acotar el análisis en ambos casos utilizamos los primeros 300 posts $^{1}$ que fueron recogidos en el periodo que abarca desde octubre de 2015 a octubre de 2016. Por otra parte, la investigación etnográfica de los mismos abarca desde febrero de 2016 a julio de 2017. Durante este año y medio se produjo un análisis sistemático diario tanto de los posts como los comentarios tomando notas de los elementos más destacables.

Así pues, los datos analizados en el apartado siguiente suponen una combinación entre lo cualitativo y lo cuantitativo, de manera que se irán entrelazando las interpretaciones de una forma global. El análisis presentado constará de las siguientes partes: una caracterización de los perfiles seleccionados donde observaremos las tipologías de imágenes que aparecen en los perfiles (tras una clasificación propia), las más gustadas y comentadas, así como los elementos textuales más significativos. Después analizaremos el relato personal de cada una de estas usuarias, a partir de algunos episodios concretos.

\subsection{Análisis y discusión}

A pesar de que los dos perfiles elegido son de naturaleza distinta, coinciden en combinar publicaciones que van de lo personal a lo profesional (puesto que ambas son madres trabajadoras) y donde la familia tiene un peso muy importante. Este tipo de contenidos coincide con la investigación de Locatelli (2017) que analiza imágenes de lactancia en Instagram, cuyos pies de foto expresan por parte de las madres el deseo de capturar la felicidad del momento, pero a la vez representar las dificultades que conlleva. También representan momentos específicos cotidianos como el baño del bebé, etc. constituyendo una suerte de diario donde el embarazo, la lactancia y la crianza son documentados y compartidos en cada momento (Locatelli, 2017, p 4). Este tipo de aproximación al relato personal como diario sería coincidente con el de nuestros casos de estudio, y además, como veremos más adelante, la lactancia es un tema central no sólo de las imágenes sino también de las discusiones. A partir de aquí cada perfil conduce a un camino muy distinto que se podrían definir como uno más afirmativo, de complicidad personal y otro caracterizado por la discusión.

\footnotetext{
${ }^{1}$ Es importante señalar que los datos que captura la aplicación no se han actualizado posteriormente para comprobar si había algún cambio en los metadatos, por ejemplo, aumentar el número de likes de una imagen, o el número de comentarios. Se trata en este caso de una decisión metodológica que tomamos en otros estudios de caso en el mismo proyecto y que aquí se replica para poder mantener el estudio comparativo entre casos.
} 


\subsubsection{Sylvia}

Sylvia (figura 1) es una mujer norteamericana de edad media que vive en una casa en el campo en el estado de Ohio (EEUU) y que se dedica profesionalmente a asistir partos naturales como matrona. Seguramente la publicación del selfie justo unas horas después de haber dado a luz a su quinto hijo la convirtió en una persona conocida, ya que esta imagen fue difundida y comentada por varios medios digitales, con lo que generó un alto grado de empatía especialmente entre mujeres en situación similar. Actualmente tiene 18.300 seguidores.

Si nos centramos en el tipo de imágenes más abundantes dentro del conjunto analizado, observamos que el selfie tiene un papel bastante minoritario (alrededor del 8\%) predominando las imágenes de niños, especialmente de sus hijos $(25 \%)$ y también de otras mujeres-madres, pues su trabajo consiste en traer niños al mundo. El porcentaje de selfies es bastante similar al que hemos encontrado en los distintos casos del proyecto en contextos muy diferentes (un festival de música, una feria de videojuegos, una manifestación o una discoteca) y por tanto vendría a confirmar, por una parte, una presencia bastante inferior a lo esperado del selfie como forma de representación social, así como un protagonismo mucho mayor del retrato (40\%), entendido éste como la representación de otros sujetos que forman parte del entorno familiar o profesional de las usuarias de la aplicación.

En este caso, el relato de su perfil recoge muchos retratos de la vida cotidiana, cuyas imágenes contienen extensos pies de foto, que tienen una gran capacidad de engancharnos a una narrativa muy personal. Esta narrativa mezcla pensamientos muy íntimos y profesionales sobre la maternidad, pero también realiza flashbacks en su historia personal para contarnos un pasado traumático del que se está recuperando todavía. Hace unos meses, por ejemplo, Sylvia comunicó la muerte de su madre, lo que desató toda una serie de pensamientos y recuerdos que fueron recogidos en varios posts consecutivos, cambiando, por tanto, la temática de vida cotidiana en presente por una incursión en sucesos ocurridos 20 años atrás. Una vez concluido este episodio catártico, ella volvió a publicar de una forma más constante sobre su actividad profesional de comadrona, ahora ya titulada.

Durante todo este tiempo Sylvia ha construido un relato muy sincero sobre la maternidad que jamás ha generado ninguna discusión entre sus seguidores. Al contrario, provoca una gran empatía. No son únicamente los contenidos -sino el tono en el que se escriben: didáctico, poético, incluso místico, que sólo generan adhesión, jamás críticas. De hecho, tal y como se observa en la nube de términos abajo, la palabra que más aparece en los pies de foto y comentarios es "love", "all", "time", "baby". Se podría decir que Sylvia controla su propio discurso sobre la maternidad, basado en buena parte en su autoridad como profesional que no es cuestionado por sus seguidoras en ningún momento.

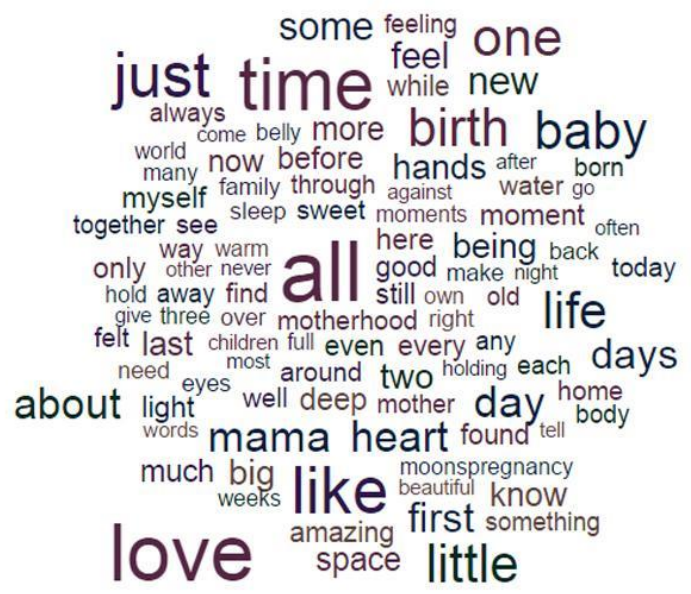

Fig. 3. Nube de palabras más frecuentes recogidas en los metadatos relativos al pie de foto 'caption' y a los comentarios de los seguidores. 
Imág nes post-matern en instagram: el selfie como narrativa personal

Así pues, podemos concluir que en este perfil se expresa un relato personal, pero también profesional, que tiene, primero, una función catártica (puesto que la publicación del relato sirve como terapia personal, por ejemplo cuando cuenta su tránsito por orfanatos en su infancia), segundo, una función pedagógica (puesto que a partir de su ejemplo se transmite una idea vinculada al parto natural y al conocimiento del cuerpo femenino) y muy recientemente, dada su consolidación profesional, se ha reforzado una función de comunicación comercial o promocional (puesto que no sólo parece ser que tiene más trabajo, sino que también muestra productos relacionados con su trabajo). Además, hay que añadir el relato familiar más descriptivo que tendría en común con muchas mujeres que comparten imágenes de sus hijos en diversas situaciones como el co-lecho, alimentación, ropa, etc. (Locatelli, 2017) y que también están presentes en el siguiente caso a analizar. Finalmente, podríamos remarcar que este perfil desarrolla un discurso sobre la maternidad basado en resaltar la naturalidad del parto y una cierta exaltación del cuerpo femenino como aquel que es capaz de producir vida. Se trata de un discurso afirmativo, puesto que sin llegar a hacer proselitismo no es contestado por las seguidoras.

\subsubsection{Marina}

Por otro lado, Marina (figura 2) es una mujer española de edad media que colabora en un programa de televisión de una cadena privada, perteneciente a un grupo mediático español muy importante. Por tanto, se trataría de una celebrity en cierto modo que tiene 479.000 seguidores en Instagram, interesado/as en su vida profesional pero también en su vida personal y por tanto se expone a un juicio constante ante ellos. Publicó el selfie al que nos referimos unas semanas después de dar a luz a su primer hijo. En su perfil aparecen también múltiples imágenes que documentan todo el proceso del embarazo y la crianza del niño. En este caso, es interesante señalar, que, tratándose de su primer hijo, ella comparte múltiples momentos y decisiones relacionadas con la crianza como el tipo de alimentación, ropa a utilizar y todos los complementos del bebé.

En cuanto a las tipologías de imagen es interesante remarcar aquí que el porcentaje de selfies es del $30 \%$, sumando selfies individuales y colectivos que incluyen también a su hijo. El 10\% corresponde a imágenes del bebé en solitario y el 19\% son retratos de otras personas. Estos resultados difieren bastante de los encontrados en el perfil de Sylvia y se aleja de los porcentajes que habíamos encontrado en otras situaciones, tal como hemos comentado. Esta abundancia de selfies se podría interpretar por su condición de personaje televisivo, pero también porque pasa mucho tiempo sola con el niño y por tanto las imágenes suyas con el bebé son las más abundantes. No es extraño, pues, que la imagen con más likes de su perfil sea un selfie ante el espejo con su hijo tras el baño diario.

Dada la condición de famosa de este caso, resulta pertinente destacar la sensación de extrema confianza con la que las seguidoras en Instagram se dirigen a las mismas. Les hacen preguntas directas o comentarios, así como les proporcionan consejos, esperando una respuesta como si de una amiga se tratase. Cuando se rechazan los consejos que no han pedido algunas seguidoras se ofenden y se justifican diciendo que son famosas y que, por tanto, se exponen a las críticas. Esta sensación de proximidad se acerca mucho al concepto de 'vigilancia' que se pone en práctica en las redes sociales. Tal como señala Marwick (2012) mientras que el rol de las tecnologías de la vigilancia ha sido bien documentado a un nivel macro, necesitamos reflexionar críticamente sobre las formas en las que la vigilancia de y entre individuos está digitalizada y normalizada a través de los medios sociales ( $\mathrm{p}$. 379).

Así pues, en el caso de Marina, la narrativa incluye imágenes muy cotidianas de ella con su hijo (ahora hijos, puesto que ha vuelto a ser madre recientemente de una niña) en diversas situaciones. En este contexto, se han producido varios episodios donde se han expresado con virulencia distintos posicionamientos en torno a la idea 
de la maternidad y crianza. Mientras su hijo era un bebé las fotografías que compartía de él solían desatar un alud de comentarios por parte de sus seguidoras. Algunos de estos mensajes eran sancionadores del modo en que estaba criando a su hijo, provocando discusiones entre las críticas y las defensoras de la libertad de la presentadora para criar a su hijo según su propio criterio. Algunos de los temas eran: el tipo de mochila que usaba para portear al bebé, si lo cubría con una gasa en el cochecito, o si le ponía un collar de ámbar. Generalmente, las situaciones eran gestionadas por Marina con bastante ironía sin responder a los comentarios negativos de las seguidoras, e incluso en algunas ocasiones 'juega' con ellas incorporando fotografías con pies de foto que sabe que generarán debate. De hecho, los temas que se discuten en sus publicaciones son tan dispares que si nos atenemos al tipo de contenidos recogidos en los metadatos de texto no se encuentra ningún patrón concreto de los temas tratados.

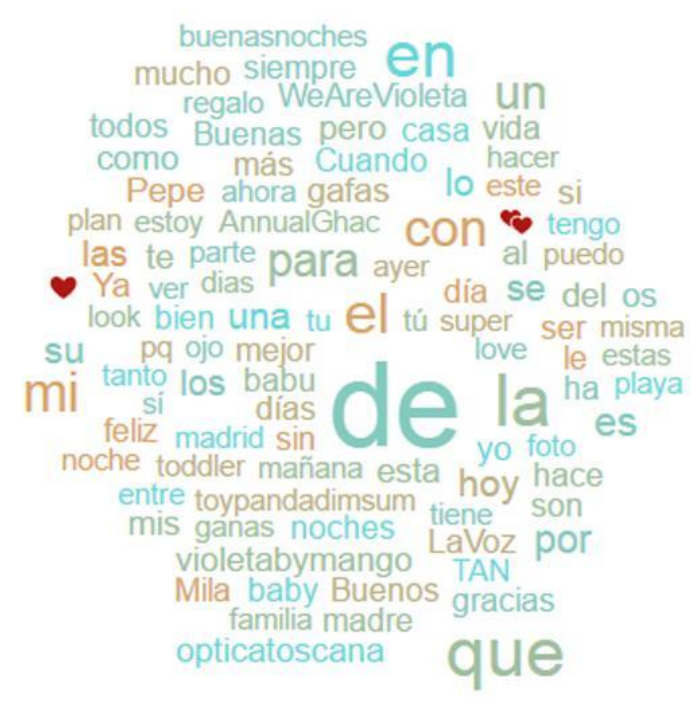

Fig. 4. Nube de palabras más frecuentes en el perfil de Marina

No obstante, lo que provoca más acaloramiento y por tanto merece un tratamiento especial es la cuestión de la lactancia. Durante los primeros meses de observación Marina fue relatando su proceso con la lactancia, pasando por distintas fases emocionales. Sin embargo, la presentadora ha sido madre por segunda vez recientemente, y publicó en su perfil que recurriría a la lactancia artificial en este caso, justificando sus motivos por cuestiones de salud. Este hecho generó una nueva oleada de críticas, no especialmente numerosas, pero sí fuertemente contestadas por su grupo de seguidoras.

En este tema en particular en las críticas y conversaciones aparecen discursos muy estructurados, incluso estereotipados, tanto desde un punto de vista más tradicional como a partir de otras tendencias alternativas sobre la crianza de los hijos. Cada una de las decisiones expresadas por esta usuaria es contestada por un grupo de mujeres que presumen de un saber superior, presentando un nivel informacional al respecto de todos los aspectos de la crianza que recriminan a la misma en muchas ocasiones. Es decir, bajo la apariencia de un consejo predomina una actitud juzgadora y recriminatoria, e incluso en algunas ocasiones se trata a la mujer de ignorante en determinados aspectos.

En cualquier caso, la cuestión principal aquí no son los comentarios negativos (que no son abundantes, aunque sí que presentan discursos monolíticos) o simplemente el hecho de criticar. En este caso la importancia radica en los discursos que se extienden en este tipo de conversaciones y en la dureza con la que se producen estos juicios. 
Imág nes post-matern en instagram: el selfie como narrativa personal

\subsection{Representaciones contemporáneas de la maternidad}

La información que ha ido emergiendo a lo largo de esta investigación nos lleva hacia el debate sobre los distintos modos de entender la maternidad en una sociedad hiper-comunicada y conectada donde aparecen múltiples temas en conflicto de tipo personal, familiar, laboral, y social. La falta de unos referentes normativos e institucionalizados como fue en el pasado más reciente, no obsta que en las publicaciones de contenido y conversaciones generadas vayan aflorando algunos arquetipos que vamos modelando en el inconsciente individual y colectivo ${ }^{2}$.

Según Nash (2014), en la segunda mitad del siglo XX hubo una reacción a la maternidad impuesta y a la sumisión de las mujeres a través del discurso católico (especialmente en algunos países como España). Frente al modelo tradicional el movimiento feminista impulsó una re-significación del arquetipo de feminidad a partir del cuestionamiento de la maternidad como único eje de la vida de las mujeres, el derecho al placer sexual y al trabajo remunerado (Nash, 2014). Sin embargo, en los últimos años este posicionamiento ha ido cambiando, y han ido resurgiendo de nuevo algunas posiciones más conservadoras.

A pesar de que las articulaciones contemporáneas de la maternidad son complejas existe un tema central en este debate: la manera en que la maternidad ha sido mitificada y mediada a través de la cultura popular (Kaplan, 2013; Woodward, 2003) y los medios de comunicación en distintos soportes. Según Green (2012), los ideales de maternidad son normalizados, nebulosos y tácitos y sirven para definir roles socialmente aceptables que se materializan en las experiencias vividas de las mujeres (Green, 2012). En particular, como propone Hall, el mito de la madre natural se filtra como un fenómeno gradual, multi-estático y multimedia (Hall, 1998). Douglas y Michaels (2005) en su análisis de las representaciones de la maternidad occidental en los medios de comunicación señalan la idealización irreal e inalcanzable de la maternidad presentada en las narrativas culturales predominantes de lo que denominan hipernatalismo (Douglas \& Michaels, 2005). Según esta visión, las madres se posicionan como las principales cuidadoras de los hijos, de manera que para tener una maternidad exitosa se requiere renunciar a la autonomía. Así, se conforma una visión centrada en el niño e idealizada de mujeres y niños que tiene poca relación con las realidades de la vida cotidiana de la mayoría de las madres (Douglas y Michaels, 2005). Esta idea es similar a la de la maternidad 'intensiva' definida como; "una ideología romántica y exigente que enfatiza la necesidad por parte de las madres de dedicar una gran cantidad de tiempo, energía y dinero al cuidado de los hijos" (Hays, 1998). De este modo, se espera que las madres sitúen las necesidades de los hijos por encima de las suyas, y además se sientan satisfechas y realizadas por este rol. (Lee, 1997 in Oton-Johnson, 2017).

Existen otros arquetipos que tratan de deconstruir este modelo idílico de un modo más explícito, mostrando también elementos negativos y contradicciones en la maternidad contemporánea. Una de ellas sería la definición de 'madre progre' que identifica Sánchez de Bustamante (2017) a partir del análisis de la webserie argentina Roxi y de los comentarios y reacciones de la audiencia. Según esta autora, el poder persuasivo del discurso de la serie puede vincularse a la constitución de un verosímil (una madre real) con la que se identifican las seguidoras a partir de "algunas vivencias que unifican una cierta experiencia de género colectiva, en el marco de determinadas coordenadas sociales (como aspectos de clase —media, media/alta - y de hábitat urbano)" (Sánchez de Bustamante, 2017, p. 249). El personaje de la serie, Roxi, establece una distancia con el arquetipo ideal (expresado en diferentes términos como hemos visto) y se aleja de la versión edulcorada del modelo de madre tradicional. La expresión de mami progre (propuesta por el personaje) evoca una maternidad que transita con contradicciones permanentes respecto a convicciones ideológicas, pertenencia de clase y gustos estéticos, generando un estado de ansiedad, insatisfacción y culpa en las madres (Sánchez de Bustamante, 2017, p. 251)

\footnotetext{
${ }^{2}$ La idea de arquetipo proviene de Jung, quien afirmaba que el arquetipo materno es consiguientemente una imagen interna propia de la mente humana que debido a su universalidad e importancia básica se encuentra presente en innumerables ritos, mitos, símbolos religiosos, sueños, fantasías, y obras artísticas de distinta índole desde la prehistoria hasta la época contemporánea.
} 
Si ponemos en relación el análisis de los perfiles de las usuarias con las visiones de la maternidad que acvabamos de esbozar, de un lado comprobamos con nuestro análisis cómo un mismo mensaje: un selfie reivindicativo, nos lleva a distintos perfiles que establecen dinámicas discursivas bastante diferentes entre sí que nos hablan de cómo entender la maternidad en diferentes sentidos. De otro lado, analizando los diferentes arquetipos y representaciones sobre la maternidad contemporánea constatamos que todos ellos se establecen en base a oposiciones (una herencia histórica que se arrastra desde los arquetipos clásicos, las figuras bíblicas y otras representaciones femeninas - Pandora, Eva o Lilith, por ejemplo).

En nuestra investigación, en primer lugar aparece una primera contraposición entre la madre real y la madre idealizada -en cuanto al aspecto físico- en la representación sobre el cuerpo de la mujer que proponen los selfies con los que esta investigación inicia. Este es el único mensaje explícitamente emitido por las mujeres analizadas, que, de algún modo alude a una segunda contraposición que aparece (mujer atractiva/mujer 'dejada'), como aquella madre perfecta de uñas pintadas y aspecto impecable, que ninguna de las dos reconoce ser, mostrando sus defectos. En este sentido, cabe señalar que a lo largo de estos dos años en ninguno de los perfiles abundan en la apariencia física, aunque el tema de la belleza aparece puntualmente en algunos posts en ambos casos por igual.

Otra contraposición que se puede entrever en los mensajes publicados por ambas usuarias es la de natural/artificial, entendida en los términos de vida rural en el campo. Este ideal está especialmente vinculado al perfil de Sylvia, y se refuerza, no tanto por su condición de madre sino por su profesión. Esta mujer en última instancia propaga la visión de una madre natural en el sentido llevar un estilo de vida sana en el campo, aunque obviamente incluye múltiples matices. En el caso del perfil de Marina, de vida urbana, esta oposición no es tan evidente puesto que la tendencia a naturalizar todos los aspectos relacionados con el parto y la crianza de los hijos es algo que sucede a nivel internacional y por tanto también está presente en este caso.

Teniendo en cuenta que ambas son madres trabajadoras la división entre trabajar solo para los hijos o fuera no se da. Así pues, ambas engendran el tipo de conflictos entre la conciliación de la vida familiar y la laboral que aparecen de forma recurrente en sus publicaciones. Este aspecto les acercaría al arquetipo mediático de la madre progre contemporánea, aunque ninguna de las dos realiza ningún tipo de mensaje de tipo político o ideológico. También es remarcable que ninguna de ellas enuncia mensajes que hagan referencia, o se puedan entender ligados al ideal de la maternidad intensa.

No obstante, sí que aparecen dichos arquetipos en los comentarios y las percepciones, así como en las discusiones generadas de un modo muy recurrente en las críticas a Marina. Los comentarios relacionados con el aspecto del cuerpo son muy frecuentes, tanto los positivos que dicen lo bella que está, como los negativos criticando los quilos que pueda haber ganado. Sin embargo, los comentarios que tienen una mayor presencia son los relacionados con el cuidado de los hijos. En este caso se producen críticas como en una ocasión en que Marina publicó en su perfil una foto del niño en una silla de coche en la misma dirección de la marcha. Algunas seguidoras le recriminaron una cierta desconsideración hacia la seguridad del niño, incluso la acusaron de arriesgar su vida. Esto nos recuerda al 'hipernatalismo', o esta forma de ejercer la natalidad que aparece en contradicción con una madre que tiene una dedicación 'normal' o basada en el 'sentido común' (comentarios de las seguidoras). Es en este punto donde se hace relevante introducir una última contradicción que aparecía apuntada de algún modo en la introducción de esta comunicación que se podría denominar 'informada/ignorante'.

Ante un ejemplo como el de la imagen del niño en la silla del coche, múltiples comentarios iban en la línea de ‘¿cómo puedes poner el niño de cara a la marcha, arriesgando su vida?'... a lo que otras contestaban 'Es que no sabe, como es madre primeriza...'. Señalaban, de este modo, la ignorancia o el no saber de Marina, frente al grupo de mujeres informadas que le daban consejos. Este episodio resulta muy significativo de este componente 
Imág nes post-matern en instagram: el selfie como narrativa personal

informacional que señalaba en la introducción y que tendría relación con una idea de profesionalización de la maternidad, que desarrollaré en el apartado de conclusiones.

\section{Conclusiones: ¿un nuevo ideal profesional e informado?}

Los comentarios negativos que critican a las madres que no saben suficiente para criar a sus hijos apuntan a lo que podríamos denominar como un proceso de 'profesionalización de la maternidad' que tendría (al menos) dos dimensiones: la primera sería una lectura literal del término a partir del cual una madre dejaría su profesión para dedicarse única y exclusivamente a la crianza de los hijos. Y en caso de no dejarla, dejaría a un lado una buena parte de esta dedicación para ejercer la denominada maternidad intensiva. La segunda dimensión de esta profesionalización sería trasladar las responsabilidades, lógica y discurso laboral-profesional al de la maternidad. Aquí es donde se pondrían en juego todos los conocimientos, competencias informacionales, etc. con el fin de realizar lo que vendríamos a llamar una maternidad exitosa o correcta. Se diferenciaría de la primera instancia en que se ponen en juego, además de los afectos y dedicación, un número de saberes que se han conseguido a partir de la información conseguida, talleres realizados, etc. De este modo, ambas dimensiones -la emocional (recogida en los mitos de la madre ideal y dedicada) y la racional (recogida en los saberes acumulados) quedarían integradas en esta idea de madres 'avanzadas' e intensivas.

Esta capa informacional, que es muy propia de la sociedad del conocimiento es un elemento consubstancial a la maternidad en la actualidad y que en casos de sobreexposición informativa se aleja cada vez más de las formas tradicionales de afrontar la maternidad, como por ejemplo, tener como referente principal a la propia madre, que transmitía este tipo de saber de forma oral. Así pues, además de la lectura de los distintos arquetipos existentes y las narrativas que proponen, en esta comunicación hemos identificado lo que se podría denominar, como hipótesis de trabajo, un arquetipo de madre 'informado', que ha emergido en este caso, más que de parte de las usuarias que hemos analizado, de parte de los comentarios y discusiones generadas. Este es un punto de partida para continuar la investigación en esta línea. 


\section{Referencias.}

BARASSI, Veronica. (2017). "BabyVeillance? Expecting Parents, Online Surveillance and the Cultural Specificity of Pregnancy Apps". Social Media + Society https://doi.org/10.1177/2056305117707188 [Consulta: 15 de junio de 2017]

BRUNO, Nicola; GABRIELE; Valentina, TASSO; Tiziana; BERTAMINI, Marco. "Selfies Reveal Systematic Deviations from Known Principles of Photographic Composition”. Art \& Perception, 2, 1-2 (2014), p. 45-58.

DOUGLAS, S., \& MICHAELS, M. (2005). The mommy myth: The idealization of motherhood and how it has undermined all women. New York, NY: Simon \& Schuster.

HALL, P. C. (1998). "Mothering mythology in the late twentieth century: Science, gender lore and celebratory narrative". Canadian Woman Studies, 18, 59-63.

FALLON, Kris (2014) "Streams of the Self: The Instagram Feed as Narrative Autobiography". Proceedings of the Interactive Narratives, New Media \& Social Engagement International Conference. http://interactiveconference.spanport.utoronto.ca/resources/Fallon.pdf [Consulta: 15 de octubre de 2015]

GEORGAKOPOULOU, Alexandra. "From narrating the self to posting self(ies): A small stories approach to selfies". Open Linguistics, 2, 1 (2016). https://www.degruyter.com/view/j/opli.2016.2.issue-1/opli-2016-0014/opli-2016-0014.xml [Consulta: 5 de marzo de 2017]

GÓMEZ, Edgar; THORNHAM, Helen. (2015). "Selfies beyond self-representation: the (theoretical) f(r)ictions of a practice". Journal of Aesthetics \& Culture, 7

GOODWIN, S., \& HUPPATZ, K. (2010). "Mothers making class distinctions: The aesthetics of maternity". In The Good Mother: Contemporary Motherhoods in Australia (pp. 69-88). Sydney: Sydney University Press.

GREEN, F. J. (2012). "Evaluating mothers in Supernanny and Crash test Mummy”. In E. Podnieks (Ed.), Mediating moms: Mothers in popular culture. McGill-Queen's Press-MQUP.

GUNTHERT, André (2014) “The conversational image”, Études photographiques, 31 Printemps 2014 http://etudesphotographiques.revues.org/3546 [Consulta: 15 de septiembre de 2017]

KAPLAN, E. A. (2013). "Motherhood and representation: The mother in popular culture and melodrama". London, UK: Routledge Hays, S. (1998). The cultural contradictions of motherhood. New Haven, CT: Yale University Press.

LEAVER, Tama. (2015). "Researching the ends of identity: Birth and death on social media" Social Media + Society, 1(1). doi:10.1177/2056305115578877 [Consulta: 15 de octubre de 2017]

LEE, C. (1997). "Social context, depression and the transition to motherhood". British Journal of Health Psychology, 2, 93108 .

LITTLER, J. (2013). "The rise of the 'yummy mummy': Popular conservatism and the neoliberal maternal in contemporary British culture”. Communication, Culture \& Critique, 6, 227-243.

LOCATELLI, Elisabeta. (2017). “Images of Breastfeeding on Instagram: Privacy Management”. Social Media + Society https://doi.org/10.1177/2056305117707190

LOPEZ, L. K. (2009). “The Redefining motherhood trhough the blogospehere”. Social media \& Society, 11, 729-747

MARKHAM, Annette. "Remix culture, remix methods: Reframing qualitative inquiry for social media contexts". DENZIN, N.; GIARDINA, M. (Eds.). Global Dimensions of Qualitative Inquiry inquiry. Walnut Creek: Left Coast Press. 2013, p. 6381

MARWICK, Alice E. 2012. “The Public Domain: Surveillance in Everyday Life”. Surveillance \& Society 9(4): 378-393. http://www.surveillance-and-society.org | ISS [Consulta: 15 de octubre de 2015]

NASH, Mary (ed.) Feminidades y masculinidades. Arquetipos y prácticas de género. Madrid: Alianza Editorial, 2014 
Imág nes post-matern en instagram: el selfie como narrativa personal

ORTON-JOHNSON, K. (2017). "Mummy Blogs and Representations of Motherhood: "Bad Mummies" and Their Readers" Social Media + Society. https://doi.org/10.1177/2056305117707186 [Consulta: 15 de junio de 2017]

PESKOWITZ, M. (2005). The truth behind the mummy wars: Who decides what makes a good mother? Chicago, IL: Seal Press.

SÁNCHEZ DE BUSTAMANTE, Marina (2016) “La mami progre. El ethos de la maternidad en el blog Según Roxi”. Letra. Imagen. Sonido L.I.S. Ciudad mediatizada Año VIII, \#15, Primer semestre 2016 Buenos Aires.

SAN CORNELIO, Gemma.; ROIG, Antoni; ARDÈVOL, Elisenda. (2017) "Selfies y eventos culturales: metodologías mixtas para el estudio de selfies en contexto". Proceedings del Congreso Comunicación y Realidad, Universidad Ramon LLull, Barcelona. (en prensa)

SENFT, Theresa M.; BAYM, Nancy K. "Selfies introduction What does the selfie say? Investigating a global phenomenon". International Journal of Communication, 9, 19 (2015) http://ijoc.org/index.php/ijoc/article/view/4067/1387 [Consulta: 15 de junio de 2016]

WOODWARD, K. (2003). "Representations of motherhood". In S. Earle \& G. Letherby (Eds.), Gender, identity and reproduction (pp. 18-32). New York, NY: Palgrave Macmillan. 